\title{
Hegemonía y resistencia en el espacio mediático: los medios de minorías étnicas
}

\section{Hegemony and resistance in the media space: ethnic minority media}

\author{
Alicia Ferrández-Ferrer; Jessica Retis
}

Cómo citar esta comunicación:

Ferrández-Ferrer, Alicia; Retis, Jessica (2020). “Hegemonía y resistencia en el espacio mediático: los medios de minorías étnicas". En: Comunicación y diversidad. Selección de comunicaciones del VII Congreso Internacional de la Asociación Española de Investigación de la Comunicación (AE-IC). Valencia, España, 28-30 de octubre, pp. 131-141. EPI SL. ISBN: 9788412023954

https://doi.org/10.3145/AE-IC-epi.2020.e08

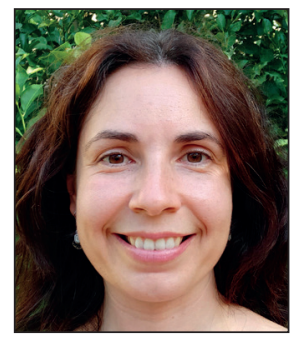

\section{Alicia Ferrández-Ferrer $\square$ https://orcid.org/0000-0002-4465-7042 \\ Universidad de Alicante \\ Facultad de Filosofía y Letras \\ Depto. de Humanidades Contemporáneas \\ Carretera San Vicente del Raspeig, s/n. \\ 03690 San Vicente del Raspeig (Alicante), \\ España}

alicia.ferrandez@ua.es

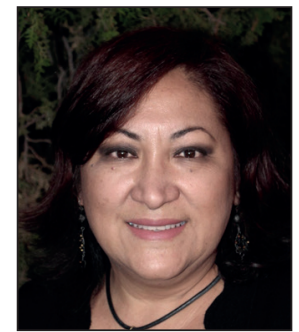

Jessica Retis

https://orcid.org/0000-0003-0665-9837

University of Arizona, School of Journalism, Master in Bilingual Journalism, Program Director. College of Social and Behavioral Sciences 845 N. Park Ave., Marshall Building Tucson, Arizona 85721, Estados Unidos jessica.retis@gmail.com

\begin{abstract}
Resumen
Existe un amplio consenso académico sobre el papel de los medios de comunicación en el fomento y mantenimiento de la hegemonía. Pero los medios también se pueden utilizar para contrarrestar los discursos hegemónicos y empoderar a las personas que no tienen voz. Este es el caso de los medios de minorías étnicas. El desarrollo de medios por parte de estos grupos ha contribuido a su inserción en la esfera pública, entendida como el espacio en el que se articulan y se negocian las cuestiones ciudadanas, y donde se produce la lucha por la imposición de significados hegemónicos sobre la realidad social. De este modo, se han convertido en una herramienta para la lucha contra la hegemonía cultural, la exclusión y la discriminación de colectivos minoritarios. Con su enorme potencial para contrarrestar no solo la representación sesgada y criminalizadora de las minorías étnicas en los medios de comunicación generalistas, sino también la "exclusión discursiva" de estos colectivos, la literatura científica ha calificado a los medios de minorías como "alternativos", y ello en una doble vertiente: por un lado, en relación a los medios generalistas, y por otro, en relación a su potencial para ofrecer nuevas voces y discursos sobre la realidad social. Este trabajo se centra en dilucidar hasta qué punto podemos considerar a este tipo de medios como "alternativos", teniendo en cuenta que, a pesar de su potencial emancipador, se encuentran sometidos a las tensiones y contradicciones del espacio mediático, que se perfila como un espacio muy complejo, influido por otros campos de poder, como son el político y el económico. En estos medios, dichas tensiones se generan además en el espacio transnacional, aportando una enorme complejidad.
\end{abstract}

\section{Palabras clave}

Diversidad cultural; Discriminación; Etnicidad; Exclusión discursiva; Esfera pública multiétnica; Hegemonía cultural; Medios alternativos; Medios étnicos; Migración transnacional; Globalización.

\section{Abstract}

There is a broad academic consensus on the role of the media in promoting and maintaining hegemony. However, the media can also be used to counter hegemonic discourses and empower people who have no voice. This is the case of ethnic minority media. The development of media by these groups has contributed to their inclusion into the public 
sphere, understood as the space in which citizen issues are articulated and negotiated, and where the struggle related to the imposition of hegemonic meanings takes place. In this context, they have become a tool in the fight against cultural hegemony, exclusion, and discrimination. Considering their enormous potential to counteract not only the biased and criminalizing representation of ethnic minorities in the mainstream media but also the "discursive exclusion" of these groups, the academic literature has described minority media as "alternative," in two aspects: on the one hand, in relation to the generalist media, and on the other, in relation to their potential to offer new voices and discourses on social reality. This work focuses on elucidating the extent to which one can consider this type of media as "alternative," considering that, despite their emancipatory potential, they are subject to the tensions and contradictions of the media space, which is emerging as a very complex space, influenced by other fields of power, e.g., political and economic. For these media, tensions are also generated in the transnational space, adding enormous complexity to the field.

\section{Keywords}

Cultural diversity; Discrimination; Ethnicity; Discursive exclusion; Multiethnic public sphere; Cultural hegemony; Alternative media; Ethnic media; Transnational migration; Globalization.

\section{Introducción}

En las últimas décadas el estudio de los medios de minorías étnicas ha cobrado cada vez más relevancia, acompañando a la creciente diversidad etnocultural de los países occidentales. Aunque su surgimiento se retrotrae hasta el siglo XIX y los migrantes que llegaban a las grandes urbes norteamericanas como Chicago, en Europa han tardado más en adquirir la importancia que tienen actualmente, en parte porque Europa fue un continente de emigrantes durante la mayor parte de su historia, y en parte porque la condición subalterna de los colectivos étnicos minoritarios impide a menudo fijar la atención en sus estrategias de producción de significados. Pero apenas un vistazo a los periódicos y revistas que migrantes, indígenas y otras minorías étnicas nacionales publican, nos permite comprender lo inadecuado de pensar en ellos como receptores pasivos de mensajes mediáticos. Muy al contrario, el análisis de sus producciones demuestra que los medios también se pueden utilizar para contrarrestar los discursos hegemónicos y empoderar a las personas que no tienen voz. Este es el caso de los medios de minorías étnicas.

Este trabajo se centra en el análisis la producción de medios de comunicación por parte de minorías étnicas en el Norte Global. Nuestra ya larga trayectoria de investigación en España, Inglaterra y Estados Unidos nos permite extraer conclusiones en cuanto a su potencial emancipador, si bien también nos obliga a ser cautas.

Indudablemente, el desarrollo de medios de comunicación por parte de minorías étnicas y migrantes ha contribuido a su inserción en la esfera pública (Habermas, 2001 [1964]) entendida como el espacio en el que se articulan y se negocian las cuestiones ciudadanas, y donde se produce la lucha por la imposición de significados hegemónicos sobre la realidad social. De este modo, se han convertido en una herramienta para la lucha contra la hegemonía cultural, la exclusión y la discriminación de colectivos minoritarios. Es por ello que la literatura científica ha calificado a los medios de minorías como "alternativos", y ello en una doble vertiente: por un lado, en relación a los medios generalistas, y por otro, en relación a su potencial para ofrecer nuevas voces y discursos sobre la realidad social.

Este trabajo se centra en dilucidar hasta qué punto podemos considerar a este tipo de medios como "alternativos", teniendo en cuenta que, a pesar de su potencial emancipador, se encuentran sometidos a las tensiones y contradicciones del espacio mediático, que se perfila como un espacio muy complejo, influido por otros campos de poder, como son el político y el económico. En estos medios, dichas tensiones se generan además en el espacio transnacional, aportando una enorme complejidad. Es por ello por lo que antes de comenzar, debemos detenernos en el complejo panorama global en el que habitamos.

\section{Minorías étnicas en un mundo globalizado}

Los procesos de globalización han acelerado la interacción étnica a todos los niveles, y son responsables de la creciente movilidad geográfica de las poblaciones, una respuesta adaptativa a las demandas del mercado global en un contexto de triunfo del capitalismo y de las políticas neoliberales. Sin embargo, a pesar de que la creciente diversidad étnica de las sociedades contemporáneas responde a las políticas e ideologías dominantes en occidente, todavía es común hallar discursos que señalan esta diversidad como una amenaza a una identidad nacional supuestamente homogénea, como si tal homogeneidad existiera o fuera posible (Fearon, 2003).

Aunque no existe una definición internacionalmente aceptada de lo que denominamos minorías étnicas o pueblos indígenas, seguiremos la propuesta de la Organización de Naciones Unidas (ONU) para referirnos a grupos étnicos o raciales en un país determinado en el que están en una posición subalterna respecto a la población o grupo étnico dominante: con frecuencia -aunque no siempre-son grupos numéricamente más pequeños que el resto de la población, no ocupan una posición sociopolítica de poder, tienen una cultura, idioma, religión o raza distinta a la de la mayoría, y sus miembros 
tienen la voluntad de preservar esas características. A menudo estos grupos afrontan desventajas en el mercado laboral, están peor en términos de educación o salud que la población de la mayoría étnica, y gran parte de los riesgos a los que se enfrentan se deben a tres factores principales: desventajas espaciales (incluyendo la segregación espacial), cultura e idioma propios, y prejuicios y discriminación (ONU, 2018, pp. 98-99). Un informe de la University of Maryland (2015, en ONU, 2018, p. 100) afirma que en el año 2006, 196 minorías étnicas o religiosas en 108 países sufrieron algún tipo de discriminación legal formal. Esto puede incluir barreras formales para el acceso a la ciudadanía, el derecho al voto y el acceso a la justicia.

La definición de la ONU de minorías étnicas incluye a los pueblos indígenas, quienes, a pesar de ser los primeros habitantes de un territorio, se convirtieron en minorías como resultado del asentamiento y colonización de sus territorios nativos por parte de otros pueblos. Las minorías étnicas también incluyen a los nacidos en el extranjero. En esta categoría debemos incluir los procesos de migración tanto voluntaria como forzada. Los últimos datos de Naciones Unidas apuntan a que en el año 2019 había alrededor de 271 millones de migrantes internacionales en el mundo, lo que supone el 3,5\% de la población mundial $(O N U, 2019)$, a pesar de que la gran mayoría no migra a través de las fronteras sino dentro del mismo país. Sin embargo, el aumento se ha hecho evidente tanto numérica como proporcionalmente, y se prevé que alcance los 405 millones para 2050 (OIM, 2018). Un informe reciente de la Organización Internacional de Migraciones (OIM, 2018) también refleja un aumento significativo en el desplazamiento debido a conflictos civiles y medioambientales. Para el año 2019, la ONU estima que el número de refugiados y demandantes de asilo era de 28,7 millones de personas, un 10,6\% del total de migrantes internacionales, de los cuales Europa recibió 3,6 millones (un 4,4\% del total de migrantes internacionales llegados ese año) (ONU, 2019).

En este contexto, los procesos migratorios, así como la gestión de la diversidad en contextos multiculturales se han convertido en temas de gran relevancia social y política, relevancia que se intensifica en su relación con los medios de comunicación. Hace una década, la OIM advirtió de que

"a pesar de la revolución en las comunicaciones, hay muchas personas que tienen información inadecuada sobre la magnitud, las implicaciones y el contexto socioeconómico de la migración” (OIM, 2011, p. 8).

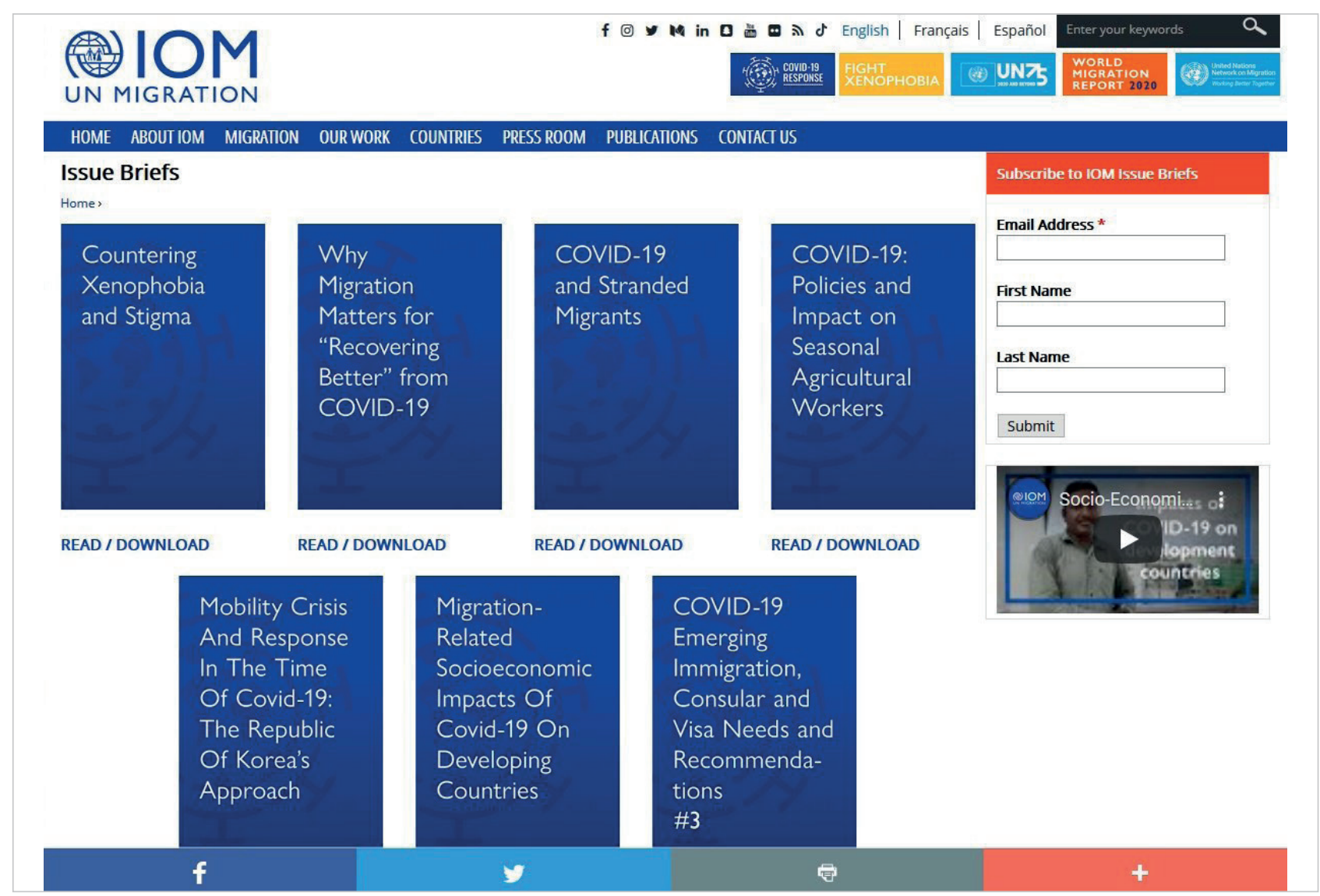

https://www.iom.int/issuebriefs 
La inmigración se ha convertido en un tema altamente politizado y se ha percibido de manera negativa, a pesar de las necesidades intrínsecas del modo de producción capitalista. Como señala el informe de la OIM, el aumento en los flujos migratorios, o más bien la percepción social de que las tasas de migración exceden los "niveles aceptables", a menudo tienen un impacto negativo en la opinión pública. En este sentido, los migrantes suelen ser acusados de robar el trabajo de los nativos, de provocar el colapso del estado de bienestar y del declive de la economía en general. Paradójicamente, y en contraste con las percepciones populares y el discurso público sobre la inmigración que afirma que ésta tiene efectos negativos para los países receptores, un estudio reciente de la Organización para la Cooperación y el Desarrollo Económico $(O C D E)$ refleja que los efectos fiscales netos de la inmigración, es decir, los impuestos que los migrantes pagan menos los beneficios y servicios gubernamentales que reciben, tienden a ser bastante pequeños y, para la mayoría de los países de la OCDE analizados en el estudio, son positivos (OCDE, 2014, en OIM, 2018, p. 4). Algunos también atribuyen la creciente ansiedad y negatividad social respecto a la migración no al aumento del flujo de migrantes, sino al ritmo al que ocurren (OIM, 2011).

Más recientemente, la recesión económica y la llamada "crisis de refugiados" iniciada en 2015 han dado alas a los partidos políticos xenófobos de todo el mundo. En Europa han logrado establecerse con fuerza en gobiernos y parlamentos de once países (frente a los dos que había en 2017) con discursos semejantes de rechazo a la inmigración, islamofobia y retórica nacionalista.

También en Estados Unidos el debate sobre la migración se ha intensificado. Aquí destaca la postura de línea dura de la administración actual, que ha prohibido la entrada al país de ciudadanos extranjeros de siete países, predominantemente musulmanes; y ha respondido a la "crisis de la inmigración", que protagonizan las caravanas centroamericanas, con la firme decisión de construir un muro a lo largo de la frontera entre Estados Unidos y México.

La mediatización de estas posturas y discursos excluyentes, junto con el endurecimiento del control fronterizo mediante políticas de detención y expulsión, ponen a los migrantes en primera línea de la opinión pública como un problema a resolver. Los principales medios de comunicación tienden a retratar a los migrantes como ilegales, delincuentes, abusadores del sistema de bienestar o como víctimas de compatriotas (Benson, 2013; Retis, 2012, 2016; Santa-Ana, 2002). En el caso de España, las imágenes trágicas de las pateras, los rescates y los naufragios en el Mediterráneo, contribuyen a la construcción de un discurso miserabilista y paternalista de la migración, que destaca la tragedia del viaje al tiempo que criminaliza tanto a los que consiguen llegar al otro lado como a las ONGs que les rescatan. En cambio, muy rara vez se muestra la migración como consecuencia de las desigualdades derivadas de los procesos históricos de colonización y conquista, o como la solución a problemas cruciales en Europa, como son el mantenimiento del sistema de pensiones, la despoblación de zonas rurales, las bajas tasas de natalidad o la falta de mano de obra en algunos sectores económicos. De esta manera, al centrarse en cuestiones de seguridad y orden público, los principales medios de comunicación siguen contribuyendo a la construcción de la migración como "pánico moral" (Cohen, 1972), desempeñando un papel importante en el mantenimiento de un sistema hegemónico que relega a las minorías étnicas y migrantes a una posición subalterna.

En ese sentido, el concepto de hegemonía cultural acuñado por Gramsci (1992) se vuelve útil para comprender el papel de las instituciones, y en particular de los medios de comunicación, en el mantenimiento de un sistema de dominación. Pero cuando existe una situación de opresión, también surgen prácticas emancipadoras, y como dice Gross (2001), no hay mejor manera de contrarrestar las prácticas y discursos sesgados de los medios que crear medios propios para hablar por uno mismo. Para algunos autores, la producción mediática de las minorías étnicas se ha convertido en un "imperativo" para evitar la pérdida cultural en sociedades multiculturales:

“¿Qué mejor estrategia podría haber para garantizar la supervivencia de las minorías que el desarrollo por su parte de sus propios medios de comunicación, transmitiendo su propio punto de vista en su propio idioma? De esta manera, se pueden tomar medidas para garantizar que las tradiciones culturales no se reduzcan al nivel del folklore y que las lenguas evolucionen de manera adaptativa a los requisitos de las sociedades modernas. Este podría considerarse el imperativo mediático de la vida moderna, un hecho reconocido por minorías en todo el mundo que han presionado por un mayor acceso a los medios de producción mediática“ (Riggins, 1992, p. 3).

\section{Hegemonía y resistencia en el espacio mediático}

La literatura sobre minorías étnicas y medios de comunicación identifica dos prácticas principales de exclusión en los medios. La primera tiene que ver con las políticas de representación de las minorías étnicas y migrantes en los medios de comunicación. Estudios realizados en todo el mundo demuestran que los medios no reflejan adecuadamente la creciente diversidad de las sociedades contemporáneas, informando sobre minorías étnicas y migrantes a través de discursos e imágenes sesgados y criminalizadores (Downing; Husband, 2005; Hargreaves, 2001; Lario, 2008; Santa-Ana, 2002; Ter-Wal, 2002). 
Por otro lado, la representación sesgada suele ir acompañada de lo que se ha acuñado como "exclusión discursiva". Para Herzog (2011), la "exclusión discursiva" significa que aquellos que están excluidos están en una posición de "irrelevancia estructural como personas":

"Esto no significa que los excluidos como tema no sean relevantes para el resto de la sociedad. Simplemente no aparecen como relevantes para la creación de su propia identidad pública, sino como meros objetos de la misma" (Herzog, 2011, p. 618).

El autor subraya que muy a menudo esta exclusión no ocurre debido a una prohibición explícita de participar, sino más bien debido a una fuerte desigualdad estructural con respecto a participar activamente en la producción del discurso. Esto se debe a una variedad de factores, como la propiedad privada de los medios, el acceso desigual a los recursos materiales o los tipos de prácticas discursivas que favorecen un tipo de lenguaje y estilo que normalmente pertenece a las clases dominantes, a expensas de otras. De esta manera, la economía política refuerza estructuralmente lo que la cultura logra informalmente, de tal manera que los medios tienden a reproducir los valores de las clases dominantes y contribuyen a mantener el status quo (Chomsky, 1997).

En referencia al caso británico, Husband señala que

"las minorías étnicas están marginadas no solo a través de las imágenes de los medios, sino también a través de su exclusión de la participación plena y equitativa en las industrias mediáticas" (Husband, 1994, p. 14).

En este sentido, la escasez de reporteros migrantes empleados en los principales medios de comunicación (Commission for Racial Equality, 2005; Ferrández-Ferrer, 2012), la escasa cantidad de fuentes de noticias de origen migrante (Retis, 2012; Santamaría, 2002; Van-Dijk, 1991), y la poca atención de los medios a este grupo social, mantiene a los migrantes y a sus intereses, prácticas y reivindicaciones políticas, invisibles. La investigación ha demostrado que, incluso cuando logran obtener un puesto de trabajo en los medios de comunicación del país de acogida, es difícil para ellos ofrecer su propia visión de la actualidad (Ferrández-Ferrer, 2012) y, como señala Husband (2005), su origen étnico adquiere una "dolorosa relevancia" cuando se enfrenta al etnocentrismo y hostilidad de sus colegas. En este contexto, Marchetti (2005, p. 67) destaca la "identidad dividida" (split identity) de los periodistas pertenecientes a minorías étnicas, que tienen que lidiar con la difícil tarea de negociar simultáneamente una identidad profesional comprometida y su identidad étnica.

Claramente, la discriminación de las minorías étnicas va más allá de su participación en los medios, ya que la exclusión discursiva y la representación sesgada son con frecuencia solo una expresión de su posición social, económica y política subalterna en la sociedad. Estas minorías han recurrido a diferentes estrategias para visibilizar su situación y luchar por sus derechos, incluyendo la ocupación del espacio público con manifestaciones y sentadas. Pero además del espacio público físico, se hace imprescindible ocupar también el espacio público mediático. En un contexto de creciente mediatización de la sociedad (Hjarvard, 2008), estar presente en los medios adquiere relevancia como garantía de existencia, y las minorías étnicas son muy conscientes de ello. Si definimos el espacio público provisto por los medios como un espacio de debate y discusión sobre lo que está en juego, la exclusión de las minorías étnicas de este espacio estaría limitando sus posibilidades como agentes activos en la lucha por el reconocimiento de sus derechos de ciudadanía. En este contexto, las minorías han demostrado ser activas en el desarrollo de sus propios medios de comunicación, con un doble objetivo. Por un lado, para contrarrestar tanto su representación sesgada como su "exclusión discursiva" de los medios generalistas, y por otro, para ejercer presión y generar opinión pública sobre la necesidad de reconocimiento y la obtención de derechos de ciudadanía. Es por ello que las minorías étnicas no pueden considerarse receptores pasivos de imágenes y discursos mediáticos, sino agentes activos en la producción de su propia identidad mediada. Y, como señala Fraser (1990, p. 67), la constitución de públicos alternativos a través de estos medios va a tener claras ventajas para los colectivos tradicionalmente ausentes de los medios dominantes, ya que permiten producir y distribuir interpretaciones alternativas de sus identidades, intereses y necesidades, al tiempo que actúan como un espacio de identificación y refuerzo de la identidad étnica del grupo.

Los estudios sobre medios de comunicación indígenas, étnicos, de minorías o comunitarios, han demostrado el poder de los medios de otorgar capacidad de agencia a sus productores y consumidores, resistiendo a través de los medios propios el discurso hegemónico y homogeneizador de los medios de la sociedad dominante. En este sentido, el desarrollo de los medios de comunicación por parte de las comunidades étnicas y migrantes contribuiría a crear una "vigorosa esfera pública multiétnica" (Husband, 2005, p. 461).

Las minorías étnicas no deben ser consideradas receptores pasivos de imágenes y discursos mediáticos, sino agentes activos en la producción de su propia identidad mediada 


\section{Medios de minorías étnicas: ¿contrahegemónicos o alternativos?}

Producidos por y/o para minorías étnicas, estos medios han sido teorizados como una alternativa, "no solo en relación a los medios dominantes sino también a su potencial para expresar ideas que son importantes y distintivas por derecho propio, que no son necesariamente contrahegemónicas, pero que siguen siendo importantes para diferentes comunidades" (Bailey; Cammaerts; Carpentier, 2007, p. xii). Al analizar este tipo de medios, los investigadores han puesto el énfasis bien en su relación (de oposición) con los medios de comunicación dominantes, o bien en su papel como servicio a la comunidad. Con respecto al carácter alternativo de los medios de minorías étnicas en comparación con los medios dominantes (mainstream), un análisis exhaustivo de estos medios nos obliga a ser prudentes y no asumir de forma acrítica su carácter contrahegemónico por el hecho de ser producidos por y/o para minorías étnicas. En este punto, la teoría de los campos de Bourdieu es útil para identificar las diversas fuerzas y actores que participan en el universo de la producción y el consumo periodístico, y que hoy en día contribuyen a limitar el poder del periodismo para influir en el mundo social de una manera crítica e independiente (ver Bourdieu, 1996a, 1996b, 2005). Bourdieu concibe un "campo" como un campo de fuerzas en el que operan una diversidad de actores, cada uno con intereses propios y a menudo contrapuestos. Los actores que participan en el campo mediático contemporáneo no solo incluyen a los medios de comunicación, con sus periodistas, editores, directores, fuentes y expertos, sino también a las empresas anunciantes y financiadores, los poderes públicos que los regulan, y por supuesto su público, que hoy en día se define por su diversidad etnocultural y por su capacidad de participación en los propios medios a través de las nuevas tecnologías. Pero los campos no son autónomos, y según Bourdieu (2005), el campo del periodismo está perdiendo cada vez más su independencia debido a la influencia de los campos de la economía y la política, que limitan la autonomía de los periodistas a través de la financiación pública y privada, y la competitividad. Por supuesto, los campos no son estáticos; cambian constantemente y, como afirma el autor, "las transformaciones del campo importan" (Bourdieu, 2005, p. 36). De hecho, debemos entender el espacio público como objeto de reconstrucción colectiva permanente y, por lo tanto, campo de batalla por la imposición de la visión legitimada de la realidad social, incluidos los discursos hegemónicos sobre la diversidad en las sociedades contemporáneas. La "democratización" de la producción de medios gracias a las nuevas tecnologías trajo importantes cambios en el campo mediático a medida que las fuentes y los discursos se volvieron más diversos. En este contexto, el desarrollo de medios de minorías étnicas en todo el mundo ha contribuido a dar una visión diferente de la realidad, desafiando las representaciones hegemónicas de una sociedad homogénea desde una posición subalterna, ya que estos productores y consumidores de medios pueden no ser formalmente reconocidos como ciudadanos o, incluso si lo son, pueden sufrir discriminación debido a su identidad étnica.

En los medios de minorías la influencia de fuerzas externas es también muy marcada, con la particularidad de que en este caso las fuerzas que participan en el campo mediático se enmarcan en el contexto transnacional, incrementando por tanto la complejidad de las interacciones e intereses en juego. Producidos y consumidos en países de destino y de origen, junto con sus productores, anunciantes, empresas de marketing, periodistas y consumidores, estos medios no se limitan al contexto nacional, sino que se caracterizan por la globalización de su capital, el desarrollo de iniciativas a escala internacional, y un interés en difundir ciertas tendencias económicas, culturales y políticas a escala mundial. Al final, la influencia de todos estos elementos determinará su potencial para desafiar la esfera pública hegemónica. Como los medios de las minorías étnicas no son ajenos a las contradicciones, las ambivalencias y las tensiones que afectan al campo mediático más amplio, la medida en que puedan considerarse alternativos o no dependerá en gran medida de los temas que aborden y las estrategias que desarrollen. Por lo tanto, sus contenidos, modos de producción, rutinas de trabajo y discursos, entre otras cuestiones, deben analizarse en profundidad (Echevarría; Ferrández-Ferrer; Dallemagne, 2015; Retis, 2006).

Con respecto a la producción de noticias, los estudios han demostrado que las prácticas de producción y las rutinas de trabajo en los medios pueden limitar su potencial democratizador, debido a la falta de periodistas y a una rutina que limita su capacidad para investigar y contrastar fuentes confiables (Ferrández-Ferrer, 2012; Saitta, 2015). Confiar en fuentes gubernamentales, judiciales o policiales, en lugar de utilizar fuentes de minorías, junto con un uso abusivo de las noticias de agencias de prensa y comunicados oficiales (de embajadas y consulados; instituciones gubernamentales locales, regionales o nacionales, etc.), hace que sea difícil ofrecer una visión alternativa de la realidad. Esto limita el papel de los periodistas minoritarios como participantes activos en la lucha contra los discursos hegemónicos sobre la migración y la diversidad cultural, y contribuye a perpetuar el dominio de determinadas fuentes como narradores -constructores- legítimos de la realidad.

Entrelazada con las prácticas y rutinas de las redacciones está la economía política. Los trabajos de Shi (2009) y Gómez (2019) muestran como también puede limitar su potencial, especialmente en un momento en el que una crisis económica y financiera los ha hecho aún más dependientes de la financiación privada. Carentes de ayudas o subvenciones públi- 
cas, el carácter gratuito de muchas de las publicaciones -una estrategia fundamental para llegar a su público- las hace extremadamente dependientes de los ingresos por publicidad. En este contexto, ha aparecido una tendencia a publicar información blanda (soft news) y evitar temas polémicos, aplicando la autocensura para satisfacer a los patrocinadores privados y mantener la publicidad (Ferrández-Ferrer, 2014, 2019b). Para contrarrestar esta situación, una investigación reciente sobre periodistas hispanos en los Estados Unidos señala la necesidad específica y crucial de financiar y apoyar proyectos de periodismo de investigación desarrollados por minorías (Retis, 2019). De lo contrario, las tensiones y contradicciones propias del campo mediático surgen también en estos medios. Por ejemplo, Gómez-Crespo (2019) destaca las contradicciones entre las líneas editoriales, caracterizadas por el deseo de desempeñar un papel social y comprometido dentro de la comunidad, y la realidad de la viabilidad económica de estos proyectos, marcada por la necesidad de construir -y vender- un público objetivo atractivo para los anunciantes. Esta mercantilización de las identidades étnicas conduce a una homogeneización de las diferencias internas, poniendo la identidad al servicio de beneficio económico (Dávila, 2001). A veces, la eliminación de las diferencias internas también responde a una cuestión de números, ya que las pequeñas comunidades étnicas pueden tener dificultades para iniciar sus propios medios de comunicación, y su única opción puede pasar por unirse a (o ser absorbidas por) otras comunidades regionales o lingüísticas más grandes. En estas situaciones, el pluralismo de los medios se reduce a los imperativos del mercado, "excluyendo aún más a las comunidades que carecen de los recursos económicos, sociales y políticos necesarios para intervenir en el llamado mercado de las ideas" (Budarick, 2018, p. 2407). Un ejemplo lo encontramos en la "colombianización" de los medios latinos en Reino Unido, donde el predominio numérico de esta comunidad, unido a su potencial de gasto, los ha convertido en el colectivo dominante en términos de producción mediática (Ferrández-Ferrer, 2014).

En este contexto, Georgiou se pregunta:

“¿desafían los medios alternativos y comunitarios a los discursos hegemónicos de estratificación étnica y de género?" (Georgiou, 2012b, p. 792).

Este interrogante nos anima a analizar los discursos e imágenes presentes en estos medios, sin suponer que entrar en la esfera mediática conlleve necesariamente una naturaleza contrahegemónica. Los medios de las minorías étnicas siguen siendo medios, y como tales no son ajenos a las luchas, negociaciones y dinámicas que afectan tanto al campo periodístico como al campo social más amplio. Como afirma Bourdieu, un cierto nivel de agencia en esta lucha por el poder no significa la emancipación de la estructura del campo en cuestión. De hecho, las prácticas y los discursos alternativos no siempre buscan una deconstrucción de los principios hegemónicos, sino que participan en la lucha por el poder dentro de un cierto "espacio de posibilidades" (Bourdieu, 1996b).

La investigación ha demostrado que los medios de las minorías étnicas ofrecen una imagen proactiva y positiva de los migrantes y la diversidad étnica, como algo inherente a las sociedades contemporáneas y un proceso histórico irreversible. En este sentido, los trabajos de Ferrández-Ferrer (2019a) y Echevarría, Ferrández-Ferrer y Dallemagne (2015) de análisis de dos de los medios para migrantes con más éxito en España, Latino y Sí se puede, muestra cómo los migrantes son representados como personas jóvenes, trabajadoras, familiares, responsables y políticamente activas, muy lejos de la representación de los medios generalistas como delincuentes o víctimas. Pero a pesar de los discursos alternativos sobre temas como los derechos de ciudadanía y la participación política, otros temas, como la identidad cultural y las representaciones hegemónicas de género, siguen sin ser cuestionados. Por el contrario, las "cuestiones relacionadas con los derechos de los migrantes, la integración, la ciudadanía, la clase, el origen étnico, el género o el capitalismo global con frecuencia reproducen regímenes dominantes de representación que coexisten con discursos más alternativos" (Echevarría; Ferrández-Ferrer; Dallemagne, 2015, p. 101).

Es importante destacar que, al afirmar que los medios de minorías étnicas no se caracterizan por prácticas de producción o financiación contrahegemónicas, no estamos negando su potencial para luchar contra la discriminación y la opresión cultural. De hecho, como demuestran numerosas investigaciones, la producción y participación en los medios se ha convertido en una estrategia importante adoptada por grupos subalternos para empoderarse, creando espacios para la reproducción y revitalización de la identidad cultural y la expresión de necesidades y preocupaciones, esta vez hablando por sí mismos. Esta es claramente una concepción diferente de su cualidad de "medios alternativos", relacionada con los intereses de la comunidad. Si partimos de la concepción del espacio público como un espacio para la discusión de asuntos públicos y la conformación de opinión pública (Habermas, 2001 [1964]), la aparición de medios específicos producidos por y/o para minorías étnicas puede proporcionar espacios de reunión, discusión y articulación de sus reivindicaciones políticas. De hecho, los medios étnicos pueden actuar como "espacios de ciudadanización" (Mata, 2006), esto 
es, como espacios para la creación de derechos y deberes ciudadanos, funcionando como vehículo para la movilización política de los migrantes (Ferrández-Ferrer, 2013) o comunidades indígenas (Wilson; Stewart, 2008), como defensores de los intereses de su público (Ferrández-Ferrer, 2012), y proporcionando espacios para debatir sobre las necesidades y preocupaciones de los migrantes y las minorías étnicas (Casillas, 2016; Retis, 2019). En este contexto, los medios de las minorías estarían combatiendo la hegemonía de diferentes maneras:

Como sistemas de representación que son complejos y ricos, desestabilizan las dualidades de un Nosotros homogéneo frente a un Otro homogéneo. A medida que se expanden a través de espacios locales, nacionales y transnacionales, desafían la concepción de la esfera pública como singular y del espacio público como contenido físicamente. Y a medida que brindan oportunidades de autorrepresentación a grupos que a menudo se encuentran al margen de la sociedad, abren la calle física y mediada para ser un espacio de presencia, posiblemente y con suerte un espacio de participación democrática (Georgiou, 2012a, p. x).

La forma en que los medios minoritarios combinan su capacidad para contrarrestar los discursos hegemónicos de la esfera pública dominante, por un lado, y para crear espacios para el reconocimiento y el refuerzo de las comunidades étnicas por otro, junto con su papel como actores políticos en el espacio mediático más amplio, abre la puerta a una gran cantidad de tipos de medios. En este sentido, una perspectiva crítica sobre los medios de las minorías étnicas mostraría la complejidad de la producción de los medios en el campo mediático contemporáneo rechazando los enfoques simplistas que suponen que la producción mediática de las minorías significa automáticamente un desafío a los discursos y prácticas hegemónicos. Esta complejidad es consistente con la idea de los medios como agentes activos en las negociaciones y luchas que tienen lugar en la esfera pública, ya que los intereses múltiples, contradictorios, superpuestos y cambiantes siempre son parte de tales negociaciones. Como dice Georgiou,

Los medios étnicos y diaspóricos... se caracterizan por paradójicas contradicciones: afirmando representar a las comunidades; aspirando a obtener beneficios; marcados por el amateurismo; promoviendo un nacionalismo a larga distancia; celebrando el cosmopolitismo u ondeando la bandera del comunitarismo... Estos medios reflejan un mundo en sí mismo: rico, poderoso, disputado y desgarrado por las luchas de poder que se producen en y con el sistema hegemónico de poder de los medios (Georgiou, 2012a, p. ix).

\section{Conclusiones}

Este trabajo pretende mostrar el potencial de los medios de minorías étnicas para combatir los discursos hegemónicos, la exclusión discursiva y la discriminación de las minorías étnicas. Nuestra larga trayectoria de investigación sobre medios étnicos en distintos contextos, tanto en Europa como en Estados Unidos, nos permite extraer conclusiones fundadas sobre el potencial emancipador de estas iniciativas mediáticas. No solo proporcionan un discurso alternativo sobre los colectivos migrantes -mucho más positivo, no estereotipado ni criminalizador- y sus aportaciones a la sociedad multicultural, combatiendo así la construcción hegemónica de la identidad nacional que está en la base de muchas prácticas excluyentes y discriminatorias. También permiten superar la exclusión discursiva de las minorías étnicas, a menudo ausentes de los medios de producción mediática, con lo que esta exclusión significa respecto a la capacidad para construir la propia imagen y discurso de las minorías.

A estas funciones debemos sumar además el carácter reivindicativo de muchos de los medios de minorías y sus periodistas y directivos, que aprovechan el potencial de los medios para dar a conocer las necesidades, opiniones y reivindicaciones de las minorías étnicas en su lucha por la extensión de derechos en el Norte global.

Ahora bien, este potencial emancipador se da en un determinado "espacio de posibilidades", como lo denomina Bourdieu. Es decir, dentro de los márgenes de acción que permite el campo mediático más amplio, y que a menudo viene determinado por las rutinas de producción, las prácticas de autocensura y los constreñimientos que impone la financiación, en un mercado altamente competitivo. Comprender estas tensiones y contradicciones con las que tratan los medios de minorías étnicas en el espacio mediático contemporáneo es fundamental para no hacer un análisis superficial de estos. Nuestra investigación en España, Inglaterra y Estados Unidos nos permite afirmar que, siendo herramientas de empoderamiento de la comunidad en un contexto de dominio cultural y exclusión política, pero afectados por las mismas restricciones económicas y políticas que afectan a otros medios, los medios de minorías étnicas parecen situarse justo en el centro del continuum entre la hegemonía y la resistencia.

\section{Referencias}

Bailey, Olga G.; Cammaerts, Bart; Carpentier, Nico (2007). Understanding alternative media. Maidenhead: Open University Press. ISBN: 9780335235056

Benson, Rodney (2013). Shaping immigration news. A French-American comparison. New York: Cambridge University Press. ISBN: 9780521887670

Bourdieu, Pierre (1996a). On television. New York: The New Press. ISBN 9781565844070 
Bourdieu, Pierre (1996b). The rules of art: Genesis and structure of the literary field. Stanford: Stanford University Press. ISBN: 9780804726276

Bourdieu, Pierre (2005). "The political field, the social field, and the journalistic field". In: Benson, Rodney \& Neveu, Erik (eds.). Bourdieu and the journalistic field. Cambridge: Polity Press, pp. 29-47. ISBN: 9780745633862

Budarick, John (2018). "Ethnic media and counterhegemony: Agonistic pluralism, policy, and professionalism". International journal of communication, v. 12, pp. 2406-2420.

https://ijoc.org/index.php/ijoc/article/view/7616

Casillas, Dolores I. (2016). Sounds of Belonging: U.S. Spanish-language radio and public advocacy. New York: New York University Press. ISBN: 9780814770658

Chomsky, Noam (1997). "What makes mainstream media mainstream”. Z Magazine. https://chomsky.info/199710

Cohen, Stanley (1972). Folk devils and moral panics. Londres: MacGibbon and Kee. ISBN: 9780261100213

Commission for Racial Equality (2005). Why ethnic minority workers leave Londres's print journalism sector. London: Commission for Racial Equality.

Dávila, Arlene (2001). Latinos Inc.: Marketing and the making of the people. Berkeley: University of California Press. ISBN: 9780520227248

Downing, John; Husband, Charles (2005). Representing 'race'. Racisms, ethnicities and media. London: Sage. ISBN: 978 0761969129

Echevarría, Lucía; Ferrández-Ferrer, Alicia; Dallemagne, Gregory (2015). “Discursive inclusion and hegemony: the politics of representation in migrant minority media". In: Ogunyemi, Ola (ed.). Journalism, audiences and diaspora. Basingstoke: Palgrave, pp. 87-103. ISBN: 9781137457226

https://doi.org/10.1057/9781137457233_6

Fearon, James D. (2003). "Ethnic and cultural diversity by country". Journal of economic growth, v. 8, n. 2, pp. $195-222$. https://doi.org/10.1023/A:1024419522867

Ferrández-Ferrer, Alicia (2012). "Sobre la experiencia laboral de los periodistas migrantes en un contexto de desregulación: entre la precariedad y la democratización del campo mediático". Comunicación y sociedad, v. XXV, n. 2, pp. 305-330. https://doi.org/10.15581/003.25.2.305-330

Ferrández-Ferrer, Alicia (2013). "Latinoamericanos en Londres: Medios de comunicación y la lucha por el reconocimiento". En: Actas del XV encuentro de latinoamericanistas españoles. Congreso internacional "América Latina: La autonomía de una región". Madrid: Trama Editorial - Ceeib, pp. 1526-1539. ISBN: 9788492755882

Ferrández-Ferrer, Alicia (2014). A la conquista del espacio público. Migración y comunicación en las ciudades globales. Tesis doctoral. Madrid: Universidad Autónoma de Madrid.

http://hdl.handle.net/10486/663047

Ferrández-Ferrer, Alicia (2019a). “Construyendo la esfera pública en la diáspora: el migrante como sujeto político en los medios de comunicación”. En: Suárez-Navaz, Liliana; Ferrández-Ferrer, Alicia y Martínez-Corcuera, Raúl (eds.). Medios de comunicación latinos: Comunicación y cultura en la España neoliberal. Donostia: Gakoa, pp. 107-124. ISBN: 97884 96993662 https://bit.ly/34niOwX

Ferrández-Ferrer, Alicia (2019b). "Towards a democratization of the public space? Challenges for the $21^{\text {st }}$ century". In: Retis, Jessica y Tzagarousianou, Roza (eds.). The Handbook on diasporas, media and culture. IAMCR-Wiley Blackwell, pp. 255-268. ISBN: 9781119236702

Fraser, Nancy (1990). "Rethinking the public sphere: A contribution to the critique of actually existing democracy". Social text, v. 25/26, pp. 56-80.

https://doi.org/10.2307/466240

Georgiou, Myria (2012a). "Foreword". In: Rigoni, Isabelle \& Saitta, Eugénie (eds.). Mediating cultural diversity in a globalized public space. Basingstoke: Palgrave Macmillan, pp. viii-x. ISBN: 9780230348776

Georgiou, Myria (2012b). "Introduction: gender, migration and the media”. Ethnic and racial studies, v. 35 n. 5, pp. 791799.

https://doi.org/10.1080/01419870.2011.628041 
Ginsburg, Faye (1991). "Indigenous media: Faustian contract or global village?”. Cultural anthropology, v. 6, pp. $92-112$. https://doi.org/10.1525/can.1991.6.1.02a00040

Gómez-Crespo, Paloma (2019). "Publicidad y uso instrumental de la identidad etnocultural en los medios de comunicación migrantes”. En: Suárez-Navaz, Liliana; Ferrández-Ferrer, Alicia y Martínez-Corcuera, Raúl (eds.). Medios de comunicación latinos: Comunicación y cultura en la España neoliberal. Donostia: Gakoa, pp. 47-66. ISBN: 9788496993662

Gramsci, Antonio (1992). Prison notebooks (edited by Buttigieg J A). New York: Columbia University Press. ISBN: 978 0231060837

Gross, Larry (2001 [1989]). “Out of the Mainstream: Sexual Minorities and the Mass Media”. En: Durham, MeenakshiGigi y Kellner, Douglas M. (eds.). Media and Cultural Studies: Key works. Malden: Blackwell, pp. 405-423. ISBN: 978 0470658086

Habermas, Jürgen (2001 [1964]). “The public sphere: An encyclopedia article”. En: Durham, Meenakshi-Gigi y Kellner, Douglas M. (eds.). Media and cultural studies: Key works. Malden: Blackwell, pp. 102-107. ISBN: 9780470658086

Hargreaves, Alec (2001). "Media effects and ethnic relations in Britain and France". In: King, Russell \& Wood, Nancy (eds.). Media and migration: constructions of mobility and difference. London \& New York: Routledge, pp. 23-37. ISBN: 9780203458549

Herzog, Benno (2011). "Exclusión discursiva. Hacia un nuevo concepto de la exclusión social”. Revista internacional de sociología, v. 69, n. 3, pp. 607-626.

https://doi.org/10.3989/ris.2009.12.21

Hjarvard, Stig (2008). "The mediatization of society. A theory of the media as agents of social and cultural change". Nordicom review, v. 29, n. 2, pp. 105-134.

https://doi.org/10.1515/nor-2017-0181

Husband, Charles (1994). A richer vision: the development of ethnic minority media in Western democracies. Paris: Unesco. ISBN: 9789231029417

Husband, Charles (2005). "Minority ethnic media as communities of practice: Professionalism and identity politics in Interaction". Journal of ethnic and migration studies, v. 31, n. 3, pp. 461-479.

https://doi.org/10.1080/13691830500058802

Lario, Manuel (2008). "La representación de la inmigración y de los inmigrantes en la prensa y en la radio: estado de la cuestión”. En: Bañón, Antonio y Fornieles, Javier (eds.). Manual sobre comunicación e inmigración. San Sebastián: Tercera Prensa, pp. 195-213. ISBN: 9788496993020

Marchetti, Dominique (2005). "Subfields of specialized journalism". In: Benson, Rodney \& Neveu, Erik (eds.). Bourdieu and the journalistic field. Cambridge: Polity Press, pp. 64-82. ISBN: 9780745633862

Mata, María-Cristina (2006): “Comunicación y ciudadanía. Problemas teórico-políticos de su articulación”. Revista fronteiras - Estudos midiáticos, v. VIII, n. 1, pp. 5-15.

http://revistas.unisinos.br/index.php/fronteiras/article/view/6113

Organización de las Naciones Unidas (ONU) (2018). “Indigenous peoples and ethnic minorities: Marginalization is the norm". In: The report on the world social situation 2018: Promoting inclusion through social protection. New York: United Nations. ISBN: 9789211303407

https://doi.org/10.18356/14642ccc-en

Organización de las Naciones Unidas (ONU) (2019). United Nations. Population Division. Department of Economic and Social Affairs. International Migrant Stock 2019 (United Nations database, POP/DB/MIG/Stock/Rev.2019).

https://www.un.org/en/development/desa/population/migration/data/estimates2/data/UN_MigrantStockTotal_2019. $x / s x$

Organización Internacional para las Migraciones (OIM) (2011). World migration report 2011. Geneva: OIM. https://publications.iom.int/system/files/pdf/wmr2011_english.pdf

Organización Internacional para las Migraciones (OIM) (2018). World migration report 2018. Geneva: OIM. https://www.iom.int/sites/default/files/country/docs/china/r5_world_migration_report_2018_en.pdf

Retis, Jessica (2006). Espacios mediáticos de la inmigración en Madrid: Génesis y evolución. Madrid: Observatorio de las Migraciones y la Convivencia Intercultural de la Ciudad de Madrid. 
Retis, Jessica (2012). "Immigrant latina images in mainstream media: Class, race, and gender in public discourse in the United States and Spain”. In: Martínez-Lirola, María (coord.). Discourses on immigration in times of economic crisis: $A$ critical perspective. London: Cambridge Scholar Publishing, pp. 29-58. ISBN: 9781443840538

Retis, Jessica (2016). "The portrayal of Latin American immigrants in the Spanish mainstream media: Fear of compassion?". The international journal of hispanic media, v. 9, pp. 32-45.

https://www.internationalhispanicmedia.org/wp-content/uploads/2016/11/IJHM_Vol9-Portrayl.pdf

Retis, Jessica (2017). "The transnational restructuring of communication and consumption practices. Latinos in the urban settings of global cities". In: Cepeda, María Elena \& Casillas, Dolores Inés (eds.). The Routledge companion to Latina/o Media. New York: Routledge, pp. 22-36. ISBN: 9780415717793

Retis, Jessica (2019). Hispanic media today: Serving bilingual and bicultural audiences in the digital age. Washington: Democracy Fund.

https://democracyfund.org/wp-content/uploads/2020/06/2019_DemocracyFund_HispanicMediaToday.pdf

Riggins, Stephen H. (ed.) (1992). Ethnic minority media: an international perspective. London: Sage. ISBN: 9780 803947245

Saitta, Eugénie (2016). “Logiques de production et de représentation d’une identité de groupe". Émulations - Revue de sciences sociales, v. 16, pp. 111-122.

https://doi.org/10.14428/emulations.016.009

Santa-Ana, Otto (2002). Brown tide rising: Metaphors of Latinos in contemporary American public discourse. Austin, TX: University of Texas Press. ISBN: 9780292777675

Santamaría, Enrique (2002). La incógnita del extraño. Una aproximación a la significación sociológica de la 'inmigración no comunitaria'. Barcelona: Anthropos. ISBN: 9788476586136

Shi, Yu (2009). "Re-evaluating the 'alternative' role of ethnic media in the US: the case of Chinese-language press and working-class women readers". Media, culture \& society, v. 31, n. 4, pp. 597-616.

https://doi.org/10.1177/0163443709335219

Ter-Wal, Jessica (ed.) (2002). Racism and cultural diversity in the mass media. An overview of research and examples of good practice in the EU Member States. 1995-2000. Viena: European Research Centre on Migration and Ethnic Relations. https://fra.europa.eu/en/publication/2002/racism-and-cultural-diversity-mass-media

Van-Dijk, Teun (1991). Racism and the press. London \& New York: Routledge. ISBN: 9780415047333

Wilson, Pamela; Stewart, Michelle (2008). Global indigenous media. Cultures, poetics and politics. London: Duke University Press. ISBN: 9780822343080 


\section{0}

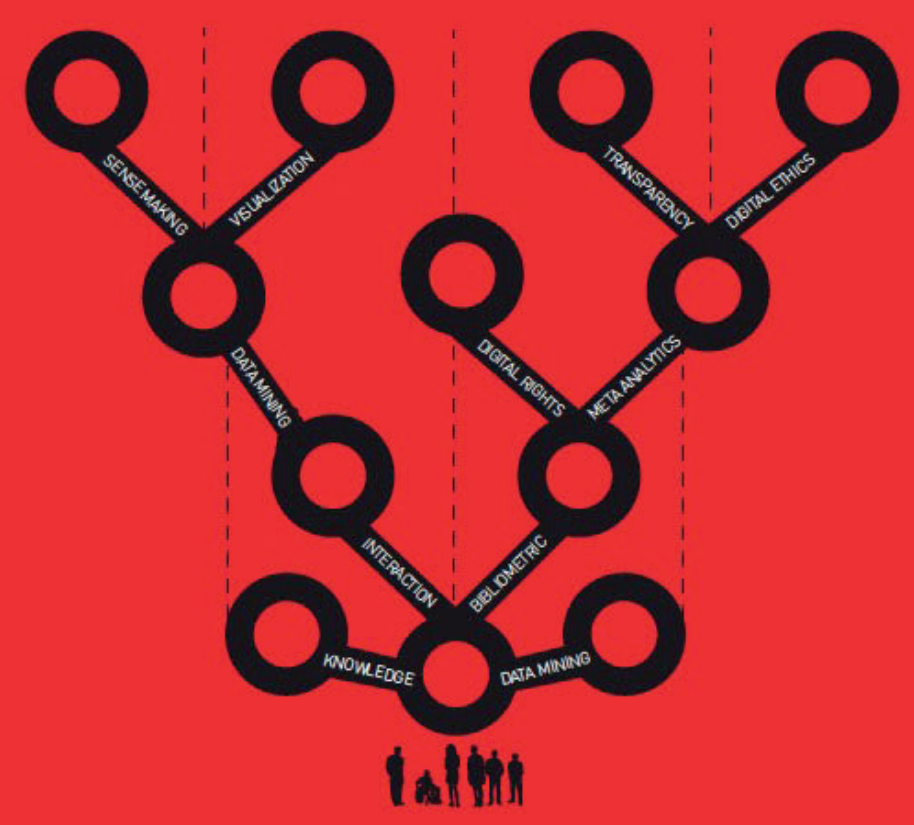

\section{Anuario ThinkEPI 2020}

Análisis de tendencias en información y documentación

Luis Rodríguez-Yunta, Director

Isabel Olea, Coordinadora 